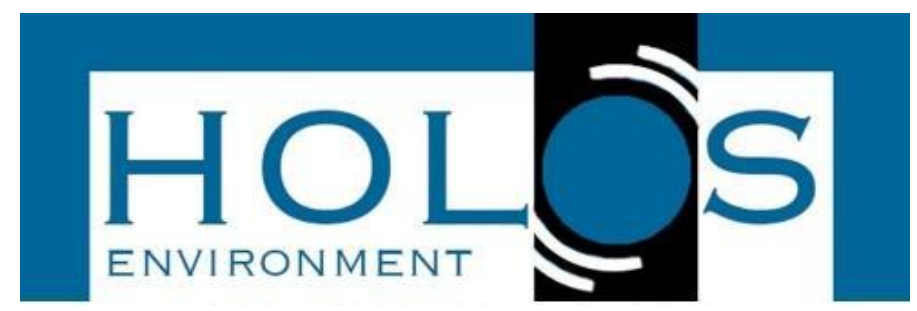

\title{
ETAPA PÓS-LICENCIAMENTO NO ESTADO DE MINAS GERAIS: ENFOQUE NA SUPRAM TMAP
}

\section{EIA FOLLOW-UP STAGE IN MINAS GERAIS STATE: SUPRAM TMAP FOCUS}

\author{
Rosane de Souza Oliveira ${ }^{1}$; Maria Rita Raimundo e Almeida ${ }^{2}$
}

Artigo recebido em: 13/05/2020 e aceito para publicação em: 26/08/2020.

DOI: http:/dx.doi.org/10.14295/holos.v20i4.12396

\begin{abstract}
Resumo: A Política Nacional do Meio Ambiente de 1981 é um importante marco na inclusão das questões ambientais nas políticas públicas brasileiras e prevê o licenciamento ambiental, constituído pelas Licenças Prévia, de Instalação e Operação, sendo, a renovação desta última uma possibilidade de acompanhamento do desempenho ambiental de um empreendimento. O estado de Minas Gerais foi pioneiro no uso do automonitoramento no acompanhamento ambiental de atividades, no entanto, existem muitas lacunas nessa prática que comprometem o processo de Avaliação de Impacto Ambiental (AIA). Assim, com este trabalho objetivou avaliar as medidas de controle e monitoramento ambiental na etapa de pós-licenciamento. Para isso, analisou-se oito processos de abatedouro e treze de laticínio, geridos pela Superintendência Regional de Meio Ambiental Triângulo Mineiro e Alto Paranaíba (Supram TMAP). As variáveis analisadas foram dividas em Variáveis Técnicas do Empreendimento (VTEs), que avaliaram o empreendimento, e Variáveis Técnicas do Processo (VTPs) que analisaram o órgão ambiental. Os resultados obtidos foram, quando possível, comparados com os obtidos na Supram Sul de Minas, para verificar influências da regionalização do órgão ambiental. A análise dos dados demonstrou que na Supram TMAP as varáveis ligadas a formalização do processo de licenciamento apresentaram classificação satisfatória, porém para as ligadas à etapa de póslicenciamento, este resultado não se repetiu. Na compação o cenário encontrado foi similar. Entretanto, destacam-se pontos de divergência de procedimentos, apontando para a falta de padronização entre as Suprams.
\end{abstract}

Palavras-chave: Renovação de LO. Condicionantes. Automonitoramento.

Abstract: In Brazil, National Environment Policy in 1981 is an important landmark in inclusion of these issues in public policies, regards the environmental licensing instrument, which is formed by the Preliminary, Installation and Operating License, the latter being revalidated over the time of the enterprise's operation activity. Minas Gerais state was a pioneer in use of self-monitoring in following-up, however, there are many gaps in this practice compromising the Environmental Impact Assessment (EIA) process. The present study aimed to evaluate the application of environmental control and monitoring measures at licensed enterprises in post-decision. In this way, eight processes slaughterhouses and thirteen dairy enterprises were analyzed, all of them managed by Triângulo Mineiro and Alto Paranaíba Regional Environmental Superintendence (Supram TMAP). Data were categorized into Enterprise Technical Variables (ETVs), which evaluated the performance of the company and Process Technical Variables (PTVs), which evaluated the environmental agency performance. The analysis of ETVs and PTVs showed that in Supram TMAP the variables related to the formalization of the licensing process presented a satisfactory classification, however for those related to the post-licensing stage, this result was not repeated. Comparing with Sul de Minas Regional Environmental Superintendence, the scenario found was similar. However, points of divergence were highlighted, revealing the lack of standardization of procedures among Regional Environmental Superintendence. In summary, the article found flaws in the post-licensing stage in Minas Gerais Stats, with a focus on Supram TMAP, which needs to be corrected.

\footnotetext{
${ }^{1}$ Universidade Federal de Uberlândia (UFU), Uberlândia, MG. E-mail: rosanesouza.oliveira@gmail.com

${ }^{2}$ Universidade Federal de Itajuba (UNIFEI), Itajubá, MG. E-mail: maria.rita.ralmeida@gmail.com
} 
Keywords: LO renewal. Condition. Self-monitoring.

\section{INTRODUÇÃO}

Após a realização da Conferência das Nações Unidas em Estocolmo, em 1972, o interesse pela proteção ambiental passa a constituir um dos direitos humanos (GRINOVER, 2014) e a ser mais discutido mundialmente, ganhando, percepção como um problema global que supera amplamente diversas questões pontuais que dominavam as décadas de 1950 e 1960 (VIOLA, 1987).

No Brasil, apesar de as primeiras leis a tratarem de recursos naturais serem da década de 1930 (SÁNCHEZ, 2008), a Política Nacional do Meio Ambiente (PNMA) - Lei Federal $n^{\circ}$ 6.938/1981 - é a principal legislação e estabelece treze instrumentos a serem utilizados de forma articulada para atingir o objetivo da compatibilização do desenvolvimento econômico-social com a preservação da qualidade do meio ambiente (PELLIN et al., 2011).

Entretanto, é a Resolução Conama $n^{\circ} 237 / 1997$ que regulamenta o processo de licenciamento ambiental brasileiro. Além de trazer definições, ela lista os empreendimentos sujeitos ao licenciamento, estabelece prazos e validade de licenças, elenca as etapas envolvidas no processo e estipula as competências (regulamentada pela Lei Complementar no 140/2011), enumerando as atividades que devem ser licenciadas pela União, Estados e Municípios (ALMEIDA, 2013).

Uma vez demonstrada à viabilidade ambiental do empreendimento pelo processo de Avaliação de Impactos Ambientais (AIA) e deferida às licenças ambientais (Licença Prévia - LP, Licença de Instalação - LI e Licença de Operação - LO), acontecem as etapas pósaprovação ou pós-licenciamento, que envolvem o monitoramento e o acompanhamento do empreendimento.

O Estado de Minas Gerais foi um dos pioneiros a institucionalizar a AIA (ALMEIDA, 2013) e, segundo Florencio (2010), a utilizar a proposição de condicionantes a serem obrigatoriamente cumpridas pelos empreendimentos potencial ou efetivamente poluidores, para a concessão e renovação das licenças. Uma das condicionantes determinadas é a realização de um programa de automonitoramento que se constitui em um importante instrumento de gestão ambiental, permitindo o acompanhamento e avaliação do póslicenciamento dos empreendimentos. 
Entretanto, um dos problemas enfrentados no processo de AIA é a falha na etapa de pós-licenciamento, que é de extrema importância para eficácia do alcance dos seus objetivos, pois é nessa etapa que as medidas para mitigar e compensar os impactos significativos identificados no EIA são implantadas e monitoradas, minimizando as consequências negativas desses impactos ou ainda compensá-los (SANTIAGO; ALVARENGA; ALMEIDA, 2016).

O sistema de licenciamento de Minas Gerais é o objeto de interesse no presente estudo, sendo, portanto, necessário entender o seu arranjo. Inicialmente, o modelo estabelecido para a superação das fragilidades do licenciamento teve como base a criação de órgãos regionais. Tais órgãos são instâncias de governança compostos por gestores regionais da Secretaria de Estado de Meio Ambiente e Desenvolvimento Sustentável (Semad) (FERNANDES; CASTRO; MARON, 2013). Foi, então, adotado um modelo interdisciplinar, compartilhado pela Fundação Estadual de Meio Ambiente (Feam), Instituto Estadual de Florestas (IEF) e Instituto Mineiro de Gestão das Águas (Igam), onde um parecer único é fornecido para cada processo de licenciamento ambiental (ALMEIDA e MONTAÑO, 2015). Ainda segundo os autores, além da aproximação das referidas entidades, foi estabelecida a regionalização na qual, sob o aspecto técnico-operacional, todos os processos de regularização ambiental passam a ser formalizados nas respectivas Superintendências Regionais de Meio Ambiente (Suprams). A estruturação do órgão ambiental, descentralizada e regionalizada, gerou maior proximidade do órgão ambiental com o empreendedor, acarretando em maior procura por regularização aumentando, de acordo com dados do Sistema Integrado de Informação Ambiental (SIAM), em quase 600\% por parte dos empreendimentos (VIANA, 2007).

Como mais uma medida de solucionar as falhas do sistema, agora mais voltadas para a etapa de pós-licenciamento, em setembro de 2016, foi publicado o Decreto Estadual no 47.042, no qual a Semad cria e dá atribuições ao Núcleo de Controle Ambiental (NUCAM), que tem como uma das suas principais atribuições acompanhar e verificar, nos processos de regularização ambiental em que foi concedida licença de operação, 0 cumprimento de condicionantes estabelecidas pelo órgão ambiental competente (MINAS GERAIS, 2016). Vale destacar que a atuação deste órgão não fez parte da presente pesquisa em função da data de sua criação e o recorte temporal utilizado.

Nesse sentido, o presente trabalho pretendeu realizar uma análise do desempenho na etapa pós-licenciamento da Supram Triângulo Mineiro e Alto Paranaíba (Supram TMAP) e compará-lo com o desempenho da Supram Sul de Minas, conforme o avaliado por 
Santiago, Alvarenga e Almeida (2016), no que compete às medidas de controle e monitoramento ambiental, verificando aspectos referentes à regionalização e padronização do órgão ambiental do Estado.

\section{METODOLOGIA}

Para o levantamento e tratamento dos dados foram empregadas metodologias quantitativas e qualitativas, a fim de se alcançar os objetivos propostos, sendo utilizado como base o trabalho de Santiago (2015), o qual estudou e analisou as questões relacionadas à etapa de pós-licenciamento na Supram Sul de Minas, para fins de comparação entre o desempenho das Suprams. No entanto, algumas variáveis precisaram ser modificadas, a fim de representarem melhor a realidade da Supram TMAP, porém, preservando, as condições que possibilitaram o estudo comparativo entre os resultados obtidos nas Suprams (Sul de Minas e TMAP).

Para a análise da etapa de pós-licenciamento, foi realizada uma triagem dos processos de empreendimentos das atividades de abatedouro e laticínio da Supram TMAP, por meio do portal Sistema Integrado de Informação Ambiental (SIAM), com LO, LOC ou renovações destas concedidas entre os anos de 2008 e 2010. Essa delimitação temporal e a tipologia dos empreendimentos foram determinadas pela representatividade no Estado, para possibilitar a análise de um período completo de vigência das licenças (até a coleta de dados em 2017) e para a comparação com os resultados do trabalho de Santiago (2015) para a Supram Sul de Minas.

Identificados os processos, iniciou-se a etapa de verificação e avaliação dos documentos componentes: Estudo de Impacto Ambiental e Relatório de Impacto Ambiental (EIA/RIMA) ou Relatório de Controle Ambiental (RCA), Plano de Controle Ambiental (PCA), Parecer único da LO ou Parecer único da Licença de Operação Corretiva (LOC), Parecer único da renovação da LO ou da LOC, Relatórios de automonitoramento, Relatório de Avaliação do Desempenho Ambiental (RADA) e autos de fiscalização e infração. Por não ter acesso a todos os documentos listados acima por meio do SIAM, foi necessária a solicitação de vista aos processos físicos no órgão ambiental.

Para a análise do cenário dessa etapa do licenciamento foram utilizadas variáveis indicativas de qualidade dos estudos, cumprimento de condicionantes e acompanhamento do órgão ambiental que consistiu na aplicação de listas de verificação com variáveis 
técnicas subdividas em itens, sendo atribuídos pesos a cada variável que somados totalizaram a nota 100 (SANTIAGO, 2015).

As variáveis foram denominadas de: Variáveis Técnicas do Empreendimento (VTE) que avaliam o desempenho do empreendimento tanto na qualidade da elaboração dos estudos, planos e projetos como no cumprimento das condicionantes da licença; e de Variáveis Técnicas do Processo (VTP), que analisam a organização dos processos e o acompanhamento dos mesmos pelo órgão ambiental, assim como o trabalho de Santiago (2015). Para a atribuição dos pesos das variáveis foram analisadas e determinadas maiores pontuações para as que representam alto grau de importância na etapa de póslicenciamento, respeitando a proporção de pesos atribuída por Santiago (2015). Cada variável foi, ainda, subdividida em itens nos quais os que representam adequação as variáveis receberam nota total e os demais pesos decrescentes à medida que se afastam do cenário esperado (Quadros 1 e 2).

Para quantificar a concordância de cada variável, seja ela VTE e VTP, utilizou-se o Índice de Concordância das Variáveis ( $\left.T_{v}\right)$, o qual expressa a razão entre a nota obtida pela variável e a máxima pontuação que ela poderia alcançar, chegando a uma escala de 0 a 1 e pelo Índice de Concordância do Processo $\left(T_{p}\right)$ que expressa a razão entre o somatório as pontuações obtidas por cada variável e o somatório da pontuação máxima possível, também em uma escala de 0 a 1. 
Quadro 1 - Varáveis Técnicas do Empreendimento e pontuação para seus itens.

\begin{tabular}{|c|c|c|}
\hline Variável & Item & Pontos \\
\hline \multirow{4}{*}{ VTE $1^{*}$} & \multicolumn{2}{|c|}{$\begin{array}{l}\text { Elaboração e entrega do PCA pelo empreendedor descrevendo as medidas mitigadoras e } \\
\text { compensatórias para os impactos significativos causados pelo empreendimento. }\end{array}$} \\
\hline & PCA foi elaborado. & 15 \\
\hline & Medidas foram adotadas, porém não foi elaborado o PCA. & 8 \\
\hline & Não, o PCA não foi entregue e não se adotou outras medidas. & 0 \\
\hline \multirow{6}{*}{ VTE $2^{*}$} & \multicolumn{2}{|c|}{$\begin{array}{l}\text { Contemplação pelas medidas mitigadoras, no PCA, dos impactos significativos identificados } \\
\text { e avaliados nos estudos (RCA ou EIA). }\end{array}$} \\
\hline & Completamente ( $\geq 90 \%$ dos impactos identificados). & 15 \\
\hline & Satisfatoriamente ( $61 \%$ a $89 \%$ dos impactos identificados). & 12 \\
\hline & Medianamente ( $41 \%$ a $60 \%$ dos impactos identificados). & 9 \\
\hline & Insatisfatoriamente (20\% a $40 \%$ dos impactos identificados). & 6 \\
\hline & Pessimamente ( $0 \%$ a $19 \%$ dos impactos identificados). & 0 \\
\hline \multirow{4}{*}{ VTE $3^{*}$} & \multicolumn{2}{|c|}{$\begin{array}{l}\text { Cumprimento das condicionantes da licença exigidas pelo órgão ambiental dentro do prazo } \\
\text { estipulado. }\end{array}$} \\
\hline & Sim, totalmente (todas). & 18 \\
\hline & Sim, parcialmente (não na totalidade). & 9 \\
\hline & Não foram cumpridas condicionantes (nenhuma). & 0 \\
\hline \multirow{4}{*}{ VTE 4} & \multicolumn{2}{|c|}{$\begin{array}{l}\text { Utilização de forma satisfatória do automonitoramento pelo empreendedor, mantendo o órgão } \\
\text { ambiental informado. }\end{array}$} \\
\hline & Sim, foi adotado o automonitoramento. & 18 \\
\hline & Outras medidas foram tomadas, mas o automonitoramento não foi exigido. & 9 \\
\hline & Não foi adotadas medidas de automonitoramento. & 0 \\
\hline \multirow{6}{*}{ VTE 5} & \multicolumn{2}{|c|}{$\begin{array}{l}\text { Conformidade dos relatórios de automonitoramento apresentados em relação aos parâmetros } \\
\text { estabelecidos na legislação. }\end{array}$} \\
\hline & Completamente ( $\geq 90 \%)$. & 18 \\
\hline & Satisfatoriamente (61\% a $89 \%)$. & 14 \\
\hline & Medianamente (41\% a $60 \%)$. & 10 \\
\hline & Insatisfatoriamente (20\% a $40 \%)$. & 6 \\
\hline & Pessimamente (0\% a $19 \%)$. & 0 \\
\hline \multirow{3}{*}{ VTE 6* } & \multicolumn{2}{|l|}{ Autuação do empreendimento no período de vigência da licença. } \\
\hline & Não. & 16 \\
\hline & Sim. & 0 \\
\hline & Total & 100 \\
\hline
\end{tabular}

*VTEs coincidentes com o adotado por Santiago (2015).

Fonte: adaptado de Santiago (2015).

Os valores encontrados nos $T_{v}$ e $T_{p}$ foram divididos em faixas de concordância de acordo com a classificação utilizada por Almeida (2010): 0,0 ト 0,2: muito baixa; 0,2 - 0,4: baixa; 0,4 - 0,6: média; $0,6 \vdash$ 0,8: alta; e 0,8 $\vdash$ 1,0: muito alta. 
Quadro 2 - Varáveis Técnicas do Processo e pontuação para seus itens.

\begin{tabular}{|c|c|c|}
\hline Variável & Item & Pontos \\
\hline \multirow{3}{*}{ VTP 1} & \multicolumn{2}{|c|}{$\begin{array}{l}\text { Preenchimento correto do Formulário Integrado de Caracterização do Empreendimento } \\
\text { (FCE). }\end{array}$} \\
\hline & FCE com preenchimento correto. & 10 \\
\hline & Havia erros no preenchimento do FCE. & 0 \\
\hline \multirow{6}{*}{ VTP 2} & Entrega dos documentos solicitados no Formulário de Orientações Básicas (FOB) & \\
\hline & Completamente ( $\geq 90 \%)$. & 10 \\
\hline & Satisfatoriamente (61\% a $89 \%)$. & 7 \\
\hline & Medianamente (41\% a $60 \%)$. & 4 \\
\hline & Insatisfatoriamente (20\% a $40 \%)$. & 1 \\
\hline & Pessimamente (0\% a $19 \%)$ & 0 \\
\hline \multirow{3}{*}{ VTP $3^{*}$} & Solicitação de documentos complementares. & \\
\hline & Não, não foram necessários complementos ao processo. & 10 \\
\hline & Sim, foram solicitados documentos complementares. & 0 \\
\hline \multirow{3}{*}{ VTP 4} & Disponibilização dos documentos referentes ao processo na pasta física ou no SIf & \\
\hline & Todos estão disponíveis em meio físico ou digital. & 10 \\
\hline & Faltam documentos no meio físico ou digital. & 0 \\
\hline \multirow{3}{*}{ VTP $5^{*}$} & $\begin{array}{l}\text { Acompanhamento periódico dos relatórios de automonitoramento entreg } \\
\text { empreendedor por parte do órgão ambiental. }\end{array}$ & les pelo \\
\hline & Os relatórios foram acompanhados. & 30 \\
\hline & O acompanhamento periódico não foi realizado. & 0 \\
\hline \multirow{3}{*}{ VTP 6} & $\begin{array}{l}\text { Realização de vistorias para fiscalizar se o empreendimento realmente está cum } \\
\text { condicionantes da licença e as leis ambientais. }\end{array}$ & prindo as \\
\hline & Ocorreram vistorias de acompanhamento no empreendimento. & 30 \\
\hline & Não ocorreram vistorias de acompanhamento no empreendimento. & 0 \\
\hline & Total & 100 \\
\hline
\end{tabular}

*VTPs coincidentes com o adotado por Santiago (2015).

Fonte: adaptado de Santiago (2015).

\section{RESULTADOS E DISCUSSÃO}

$\mathrm{Na}$ fase de triagem dos processos, foram identificados 21 (Figura 1) com as características necessárias para o estudo, sendo treze de empreendimentos de laticínios, D-01-06-6 segundo a DN Copam nº 74/2004 (COPAM, 2004), e oito de abatedouros, D-0103-1 segundo a DN Copam n 74/2004 (COPAM, 2004). Para a identificação destes, foi adotada a nomenclatura de "L", para identificar os laticínios, seguido dos números de 1 a 13 e "A" para abatedouros, seguido dos números de 1 a 8. Cabe destacar que uma nova DN está em vigor para reger o processo de licenciamento ambiental em MG, a DN Copam $n^{\circ}$ 217/2017; no entanto, era a DN Copam n 74/2004 a legislação vigente no âmbito dos processos analisados. 
Figura 1 - Localização dos empreendimentos referentes aos processos identificados na triagem

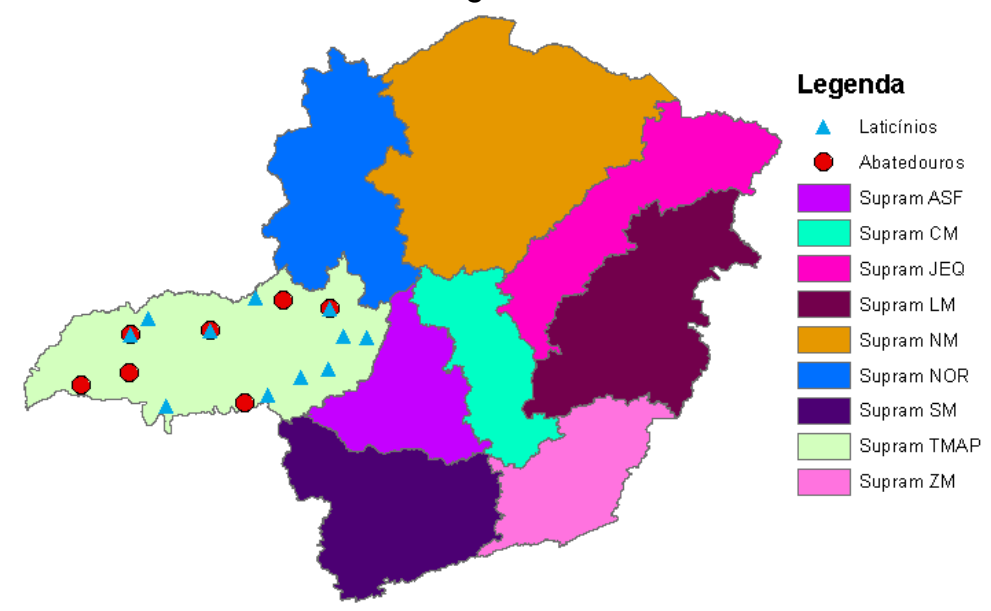

*Há sobreposição de localidades

Fonte: Elaborado pelas autoras.

Como relatado, nem todos os documentos necessários estavam disponíveis no SIAM, sendo que foi solicitada vista dos processos físicos. Porém, as solicitações de vista foram protocoladas nos meses de março e abril de 2017, sendo informado pelo servidor responsável pelo protocolo prazo de trinta dias para a disponibilização dos documentos, mas o órgão ambiental não cumpriu tal prazo, sendo as primeiras pastas analisadas em maio de 2017 seguidas de autorizações de vista em setembro e dezembro do mesmo ano. Perguntado sobre o atraso, foi informado que, na ocasião, o setor de arquivo contava com apenas um servidor para atender as demandas internas, dos analistas da regularização, fiscalização e jurídico, e as externas, Ministério Público e sociedade em geral, não sendo possível o atendimento das solicitações em tempo hábil. Dessa forma, apenas $28 \%$ das solicitações de vista foram atendidas, o que demonstra a dificuldade de acesso às informações públicas relacionadas ao licenciamento, podendo impactar no papel da sociedade na etapa pós-licenciamento que, segundo Sánchez (2008), também pode participar do processo de acompanhamento, fiscalizando e denunciando as ações de empreendimentos implantados.

Em relação ao SIAM, poucos documentos estão disponíveis, cenário este que vai ao encontro com o observado por Fonseca e Resende (2016), que detectaram um baixo nível de informatização dos documentos referentes à fase de acompanhamento de empreendimentos licenciados, não estando disponíveis os relatórios técnicos de automonitoramento, o que faz necessária a verificação do documento físico.

Notou-se, ainda, que a maioria dos empreendimentos foi licenciada com LOC, indicando que se trata de regularização de empreendimentos já em operação ou que 
perderam o prazo de renovação da licença, o que descarta a possibilidade de discussão sobre alternativa locacional e possibilidade de se evitar ou mitigar os impactos de instalação dos empreendimentos ou, ainda, a liberação para operar de empresas que não apresentam desempenho ambiental adequado.

As licenças concedidas em caráter corretivo para as atividades analisadas somam $71,4 \%$ dos processos estudados, número expressivo visto que essa modalidade de licenciamento visa à regularização apenas de atividades que operavam anteriormente as normas ambientais (ALMEIDA, 2013), no caso, o Decreto Estadual no 21.228/1981 (MINAS GERAIS, 1981). Dessa forma, as funções preventivas e de planejamento atribuídas ao licenciamento ficam prejudicadas (SILVA, 2009). Além do mais, fere o Principio da Prevenção que prevê a identificação e a adoção de medidas de mitigação dos danos ambientais da instalação e operação de empreendimentos (BRASIL, 1988), não possíveis no licenciamento corretivo.

Em relação às VTEs, foram mensuradas as concordâncias dessas variáveis e calculados Índices de Concordância de Variáveis (Figura 2) e do Processo (Figura 3). Para os processos em que não foi possível acessar ao documento, a avaliação recebeu a denominação não se aplica.

Figura 2 - Resultados dos Índices de Concordância de

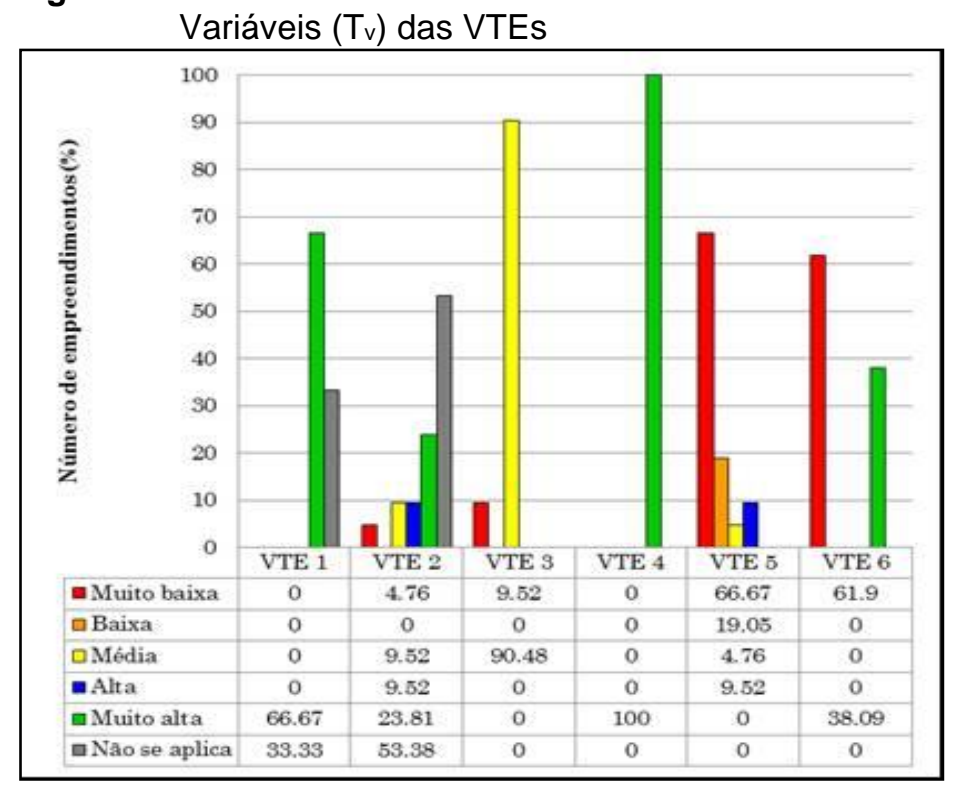

Fonte: Elaborado pelas autoras

Com a aplicação da escala de classificação (Figura 2), pode-se observar que, dos empreendimentos em que foi possível aplicar as VTE 1 (entrega do PCA) e VTE 2 (medidas 
do PCA englobam os impactos levantados no RCA), todos apresentaram concordância "Muito alta" (66,67\%). Porém, cabe ressaltar que esse procedimento é realizado no período pré-decisão e tem características burocráticas, visto que é a identificação dos impactos significativos da atividade e o planejamento das ações de mitigação e compensação destas, sendo necessário avaliar como estas ações propostas são efetivamente implementadas.

Já ao analisar a VTE 3, que indica o cumprimento de condicionantes impostas na concessão da licença, ou seja, o desempenho na etapa pós-decisão, a maioria dos empreendimentos $(90,48 \%)$ apresentou concordância "Média", o que demonstra que o cumprimento e execução do planejamento elaborado e entregue na etapa anterior não são realizados de forma satisfatória, reforçando a lacuna entre projeto e execução, que, na prática, atribui a AIA um caráter meramente burocrático como evidenciado pela CNI (2013).

Entretanto, é interessante notar que em alguns pareceres técnicos os servidores responsáveis pela análise do cumprimento de condicionantes consideraram como cumpridas as condicionantes relacionadas aos empreendimentos $L 1, L 5, L 6, L 7, A 1, A 2$, A6 e A7, mesmo estas sendo cumpridas fora do prazo, com parâmetros não estando dentro da legislação ou de forma incompleta. Estes fatos podem estar relacionados à característica da Semad em trabalhar com uma equipe técnica não fixa, ou seja, a equipe que regulariza o empreendimento não é a mesma que realiza o acompanhamento ou a renovação da licença, podendo faltar ao analista o conhecimento das etapas anteriores ou mesmo envolver um caráter de subjetividade na análise dos documentos.

Este cenário se repete para as VTE 4 e VTE 5 que se referem, respectivamente, a adoção do automonitoramento na concessão da licença, principal característica da etapa pós-licenciamento, e a entrega efetiva dos relatórios, respeitando a periodicidade e parâmetros legais. A VTE 4 indica que para todos os processos analisados foi solicitado o automonitoramento, porém alguns pareceres técnicos evidenciaram, mais uma vez, a falta de padronização de procedimentos, visto que foram solicitados automonitoramento de parâmetros não contemplados na normatização ambiental brasileira, como cloretos no solo e efluentes líquidos, além de informações controversas em relação à periodicidade, sendo as análises solicitadas trimestralmente e o envio de relatórios mensalmente.

Ao verificar a VTE 5, a maioria dos empreendimentos obteve concordância "Muito baixa", ou seja, $66,67 \%$ dos empreendedores não entregaram os relatórios de automonitoramento em conformidade com os parâmetros legais. É importante lembrar que 
esse percentual pode ser diferente, pois não foi possível o acesso a toda a documentação dos processos devido à dificuldade de acesso a informações na Supram TMAP.

A VTE 6 demonstra a porcentagem de empreendimentos autuados, em que $61,90 \%$ dos processos analisados, o empreendedor foi multado pelo não cumprimento da legislação ambiental. Pode-se destacar como autuações devido a questões ligadas diretamente a etapa pós-licenciamento as recebidas por L1, L7, L9, L11, L13, A2, A3, A5 e A7. Os casos mais graves foram de L8, L9, A2 e A4 em que os autos de infração são em relação ao não cumprimento de condicionantes, entre elas o automonitoramento, o que levou ao indeferimento das renovações das Licenças de Operação desses empreendimentos, sendo, então, reorientados para o licenciamento corretivo, ou seja, durante a vigência da LO, o desempenho ambiental dessas empresas foi insatisfatório e, mesmo assim, eles continuam a operar usando o artifício do licenciamento corretivo. Destaca-se, ainda mais, a situação de A2 que está em funcionamento na jurisdição da Supram TMAP desde 1993 e não obteve renovação de nenhuma LO ou LOC concedida, chegando a alterar sua razão social e iniciar novo processo de LOC sem o histórico de indeferimentos, trazendo à tona a fragilidade do sistema utilizado pelo estado de Minas Gerais, que não é capaz de identificar o registro de processos abertos no mesmo número de Cadastro Nacional da Pessoa Jurídica (CNPJ) e evitar duplicidades.

Em relação ao desempenho geral dos empreendimentos no cumprimento das variáveis analisadas, tem-se a Figura 3 que apresenta os resultados do $T_{p}$ na escala de classificação. O nível de concordância das variáveis, tanto para laticínios como para abatedouros, ficaram em torno de "Média" e "Baixa", ou seja, a maioria dos empreendimentos analisados não cumpriu satisfatoriamente as variáveis analisadas, o que reflete em um baixo desempenho ambiental. Assim como destacado por Prado Filho e Souza (2004), Sánchez e Gallardo (2005) e Brasil (2008), um dos problemas enfrentados pelo licenciamento ambiental brasileiro são as irregularidades no cumprimento de condicionantes e de medidas de acompanhamento.

Para análise das VTPs, que mensuram o desempenho do órgão ambiental na etapa pós-licenciamento, ou seja, o acompanhamento da implantação e cumprimentos das condicionantes e conformidade legal dos processos de licenciamento durante a vigência da licença concedida, também foram calculados o Tv (Figura 4) e o Tp (Figura 5).

As variáveis VTP 1 e VTP 2, as quais indicam o preenchimento correto do Formulário de Caracterização do Empreendimento (FCE) e a entrega dos documentos solicitados pelo Formulário de Orientação Básica (FOB) na formalização do processo de licenciamento, 
respectivamente, apresentaram concordância "Muito alta" para a maioria dos empreendimentos: $71,43 \%$ dos empreendedores preencheram corretamente o FCE e $95,24 \%$ destes entregaram todos os documentos solicitados pelo FOB, o que indica entendimento por parte dos empresários e consultores das informações solicitadas pelo órgão ambiental e coerência da documentação solicitada pelos técnicos ambientais, visto que foi possível a entrega de todos eles.

Figura 3 - Resultados dos Índices de Concordância Processo ( $\left.T_{p}\right)$

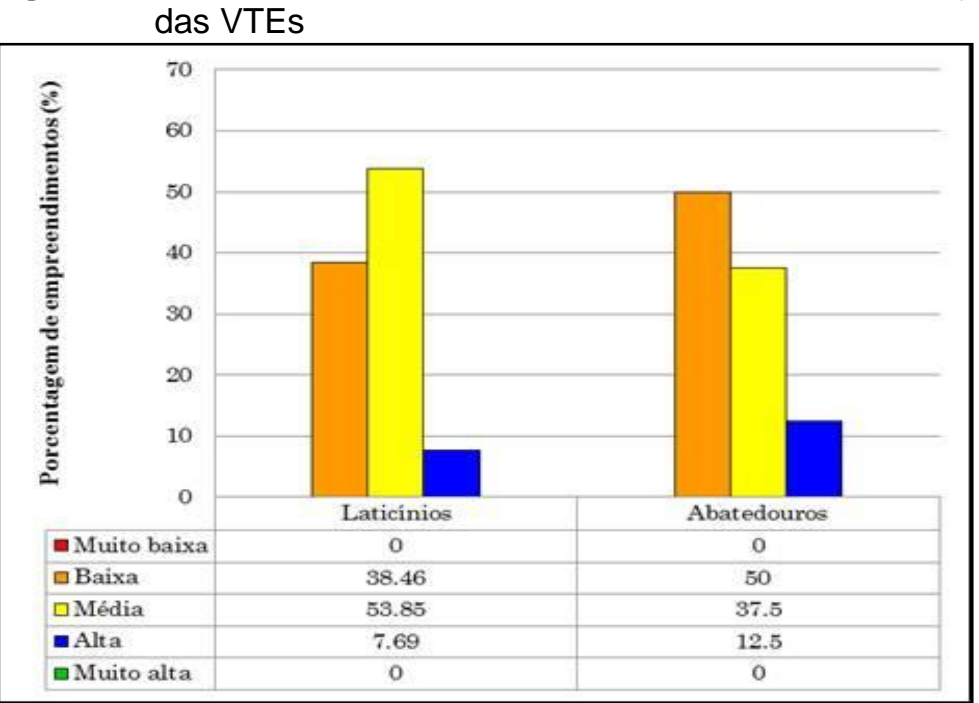

Fonte: Elaborado pelas autoras.

Figura 4 - Resultados Índices de Concordância de Variáveis ( $\left.T_{v}\right)$ das VTPs

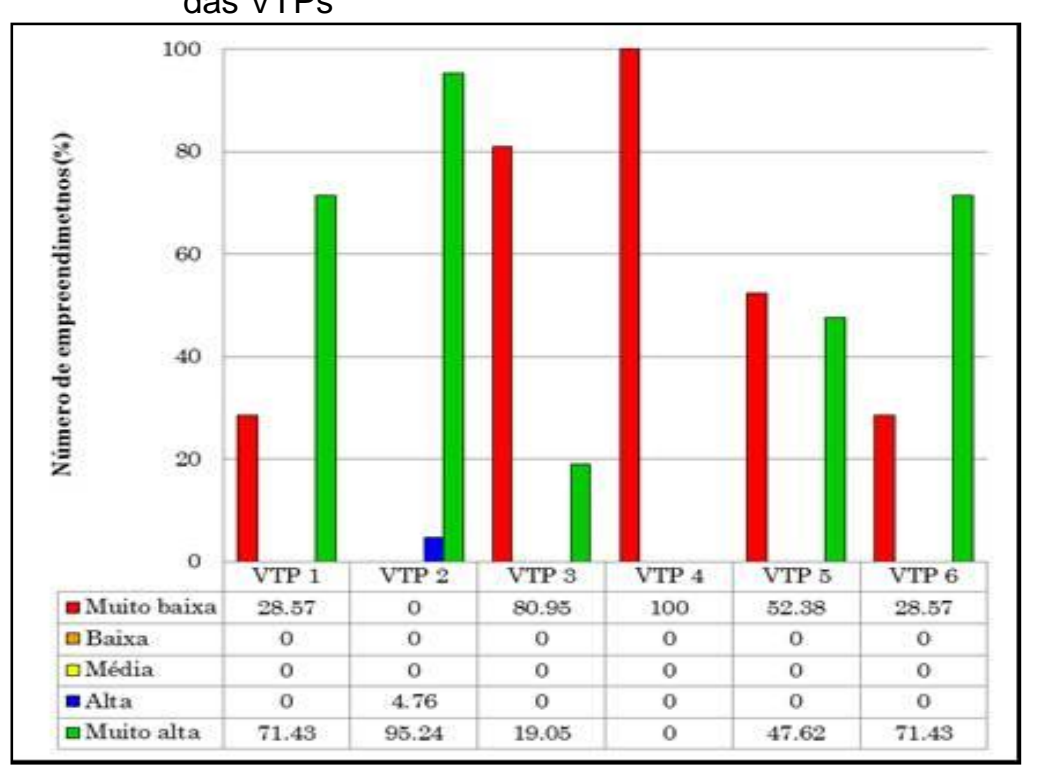

Fonte: Elaborado pelas autoras.

Por outro lado, $4,76 \%$ dos processos foram formalizados sem a entrega de todos os documentos, o que não poderia acontecer visto que a formalização do processo só deveria 
ocorrer com a entrega de todos os documentos solicitados pelo FOB (MINAS GERAIS, 2018).

A entrega do FCE e dos documentos referentes ao FOB faz parte da etapa prédecisão, com características de caracterização e confirmação de informações. Porém, quando se analisa a VTP 3 , que indica o número de processos em que houve solicitação de informações complementares, a maioria dos processos já apresenta concordância "Muito baixa", com 80,95\% dos processos apresentando documentos complementares. Esse alto número pode representar uma má qualidade dos estudos entregues como já observado por outros autores (SILVEIRA, 2006; SCHERER, 2011; ALMEIDA, ALVARENGA; CESPEDES, 2014) ou ainda uma deficiência por parte do órgão ambiental ao emitir o FOB, podendo refletir problemas na análise do FCE pelo próprio órgão ambiental, realizada de forma superficial devido à grande demanda de solicitações, gerando FOBs deficitários, visto que é impossibilitada a verificação das particularidades de cada empreendimento, fazendo necessária a solicitação de complementos para viabilizar a análise.

Passando para a VTP 4, que indica a disponibilidade dos documentos integrantes dos processos de licenciamento, tanto na pasta física como eletrônica (SIAM), nenhum processo apresenta concordância total com a variável. Isso indica que esses documentos de domínio público não estão acessíveis à sociedade, dificultando a participação popular prevista em lei (CONAMA, 1997) e, ao que parece, também não estão disponíveis ou de fácil acesso aos analistas técnicos do órgão ambiental, o que compromete e/ou atrasa a avaliação dos processos realizada por eles.

Em relação ao acompanhamento do desempenho ambiental dos empreendimentos durante a vigência da licença, a VTP 5, referente ao acompanhamento do órgão ambiental dos relatórios entregues no pós-licenciamento, retrata que ocorre negligência por parte da Supram TMAP, visto que 52,38\% dos processos analisados não apresentaram indícios de acompanhamento dos relatórios periódicos de monitoramento, sendo verificados, apenas, no momento da renovação da licença.

Estes resultados trazem à discussão as questões referentes às condições de trabalho e número insuficiente de servidores para cumprir estas funções, refletindo, além do mais, na qualidade e cuidado em que estes analistas podem dispor para cada processo, o que pode ser exemplificada na aplicação da DN Copam n¹7/1996, a qual garante a empreendimentos sem autos de infração, tramitados e julgados pelos últimos três anos, o benefício de acréscimo de dois anos na validade da renovação da licença e para os que 
incorreram em infrações o decréscimo dos mesmos dois anos na vigência da renovação da licença, observada somente para o processo referente à $A 7$.

Já a variável VTP 6 , indicativa da realização de vistorias pelo órgão ambiental, apresenta $71,4 \%$ de concordância "Muito alta", o que indica a presença de autos de vistoria/fiscalização na maioria dos processos analisados. Porém, vale destacar que não há diferenciação entre as vistorias ou fiscalizações de rotina com as realizadas a atendimento a denúncias, não podendo, portando, ser afirmado que existe uma escala de acompanhamento dos empreendimentos na etapa de pós-licenciamento no período analisado. Pelo contrário, foi observado que estas vistorias, devido à presença de autos de infração vinculados à Política Militar Ambiental de Minas Gerias (PMMG), foram, em grande parte, originados de demandas trazidas por órgãos públicos ou da sociedade em geral, não sendo uma iniciativa do órgão ambiental.

Enfim, para a análise do desempenho geral do órgão ambiental em relação aos processos analisados, tem-se a Figura 5 que apresenta os resultados do $T_{p}$.

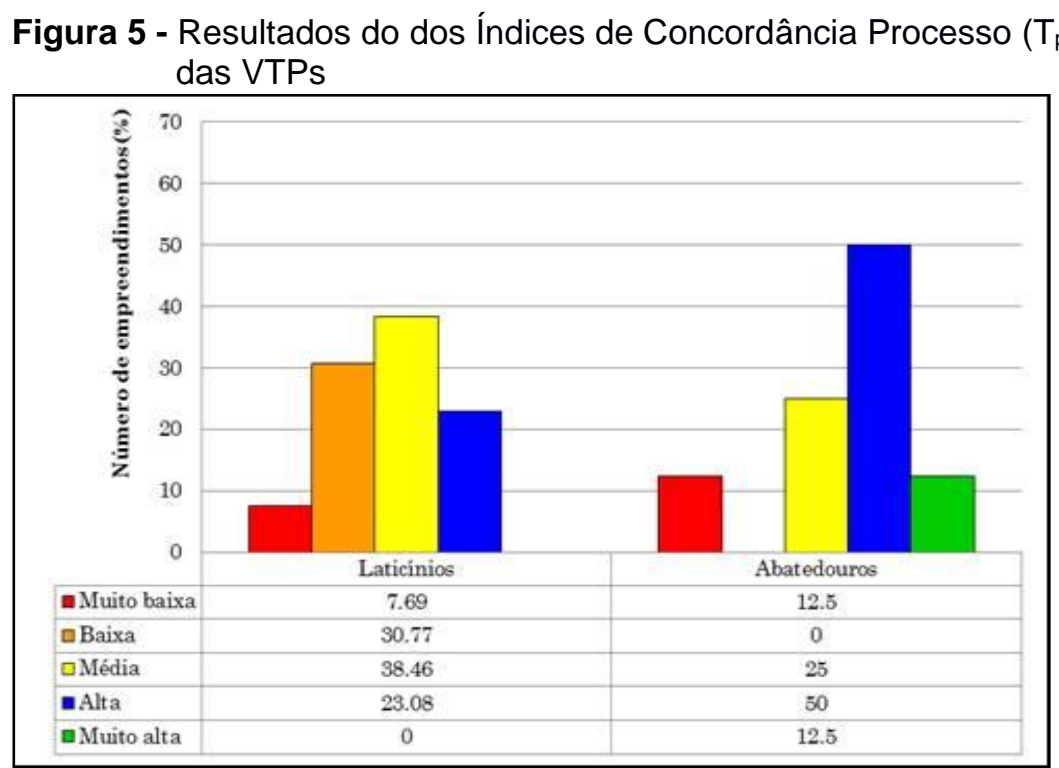

Fonte: Elaborado pelas autoras.

Fica evidenciada, na Figura 5, uma diferença de comportamento do órgão ambiental entre as duas tipologias de atividades analisadas, sendo predominante uma concordância "Média" para os laticínios e "Alta" para os abatedouros. Esse comportamento pode ter relação com o fato dos empreendimentos da atividade de abate de animais serem 
classificados, na sua maioria, como classe 6, com porte e potencial poluidor/degradador grandes (COPAM, 2004), recebendo maior atenção do órgão licenciador.

Com o observado dos resultados, foi possível traçar um perfil para a etapa de póslicenciamento na Supram TMAP. Como várias variáveis foram iguais às do estudo de Santiago (2015), tornou-se possível uma análise comparativa entre as Suprams Sul de Minas e TMAP, apresentada na Figura 6 para as VTEs (1, 2, 3 e 6) e a Figura 7 para as VTPs (3 e 5).

Figura 6 - Comparação entre os Índices de Concordância de Variáveis (Tv) para as VTEs da Supram Sul de Minas (a) (Santiago, 2015) e da Supram TMAP (b) (resultado deste trabalho)
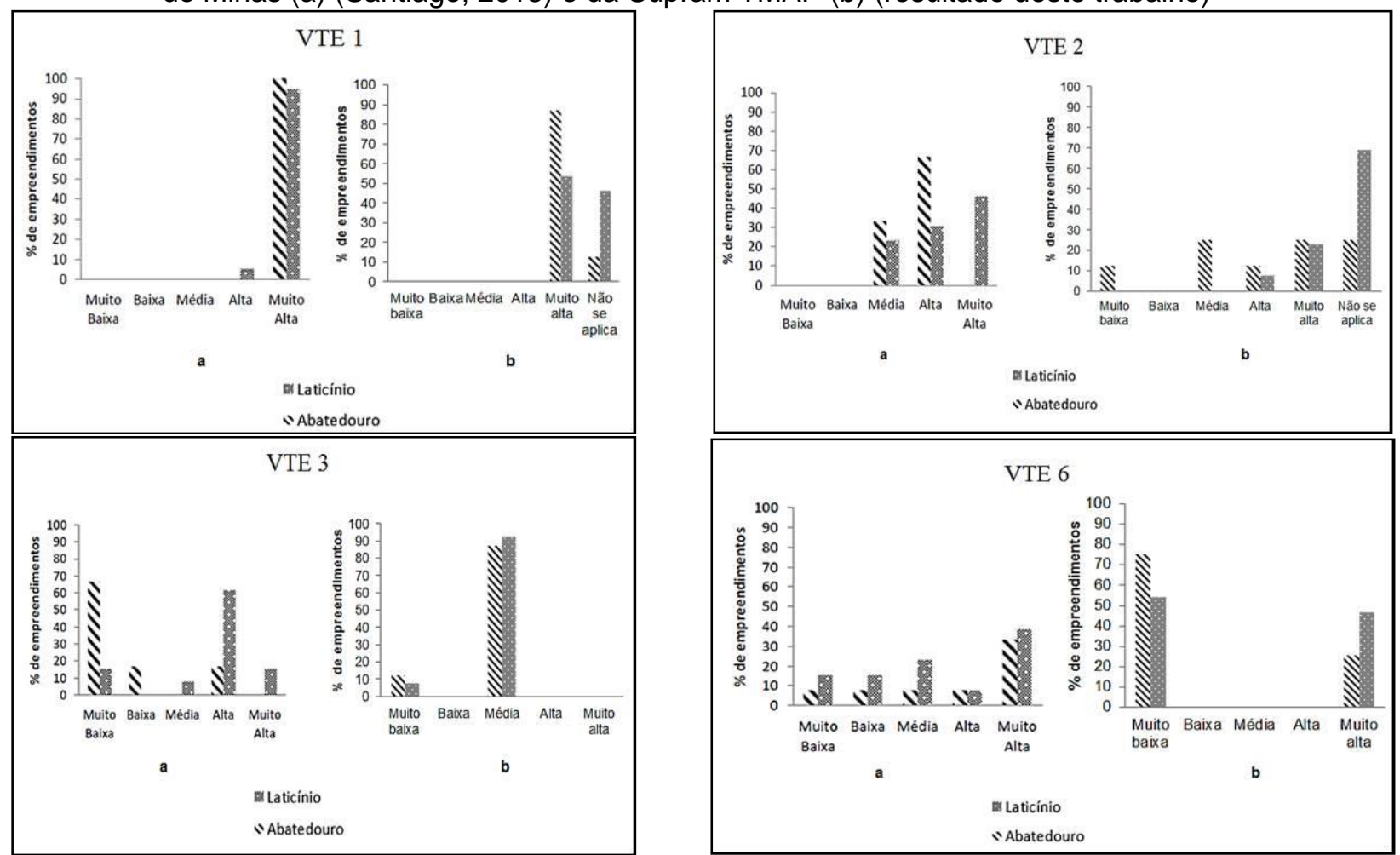

Fonte: Elaborado pelas autoras.

Em relação à VTE 1, que trata da entrega do PCA, o desempenho dos processos das duas regionais apresentou comportamentos semelhantes (Figura 6), em que a maioria dos empreendimentos apresentou concordância "Muito alta", destacando que a atividade de abate de animais obteve maior número de processos classificadas nessa faixa que a atividade de laticínio em ambas as Suprams. Entretanto, cabe ressaltar que Santiago (2015) obteve acesso a todos os documentos necessários para análise nos processos analisados, fato que não se repetiu na Supram TMAP, em que as VTE 1 e VTE 2 não puderam ser aplicadas a todos os empreendimentos.

A classificação dos empreendimentos na VTE 2 (Figura 6), referente à contemplação dos impactos significativos identificados no RCA nas ações do PCA, para Supram TMAP 
demonstrou comportamento menos uniforme que o retratado na regional Sul de Minas. Na Supram Sul de Minas, os empreendimentos obtiveram classificação entre "Média" e "Muito alta", enquanto que na TMAP foram escalados em, praticamente, todas as classes, apresentando alguns processos com a classificação "Muito baixa". Lembrando que a Supram TMAP também apresentou o "Não se aplica" devido à indisponibilidade de documentos para as vistas. Estes resultados obtidos podem indicar uma variação maior na qualidade dos PCAs encontrados na Supram TMAP, nos quais não apresentaram ações suficientes para mitigar ou compensar os impactos significativos encontrados nos RCAs. $O$ mais grave é que estes documentos foram protocolados, aceitos e aprovados como válidos pelo órgão ambiental reforçando o caráter de cumprimento de formalidade como destacado por Prado Filho e Souza (2004).

Já para VTE 3 (Figura 6), que trata do cumprimento de condicionantes, é na Supram Sul de Minas que os empreendimentos apresentam comportamento pouco uniforme e ainda com uma diferenciação expressiva entre as duas atividades econômicas estudadas, estando, predominantemente, abatedouros com $66 \%$ de concordância "Muito baixa" e cerca de $60 \%$ dos laticínios classificados como "Alta"; enquanto que na TMAP as atividades foram classificadas com cerca de 90\% como "Média", o que pode demonstrar maior uniformidade nos procedimentos empregados nesta última regional. Entretanto, observando qualitativamente os dados, na Supram Sul de Minas ocorre empreendimentos nas classificações "Alta" e "Muito alta", demonstrando que nessa regional há maior índice de cumprimento de condicionantes do que na Supram TMAP, na qual nenhuma das empresas está nessas classes, sugerindo que mesmo sem cumprir todas as condicionantes solicitadas as empresas continuam licenciadas.

Em relação à VTE 6, referente a autos de infração, foi observado, na Supram TMAP, a tendência apresentada na Figura 5, no qual a maioria dos empreendimentos da atividade de abatedouro foi classificada como "Muito alta" e de laticínios como "Muito baixa". Foi levantada a hipótese de que essa tendência poderia estar relacionada à classe dos empreendimentos, visto que os abatedouros são classes 5 e 6 , tendo maior atenção da fiscalização do órgão ambiental.

Em relação às VTEs, de forma geral, nota-se que os empreendimentos analisados pelas duas Suprams apresentaram comportamentos semelhantes e de melhor desempenho nas variáveis ligadas a etapa pré-decisão (VTE 1 e VTE 2), de caráter mais burocrático. Quando se verifica as variáveis voltadas para a etapa pós-decisão, o desempenho encontrado nas duas regionais começa a se diferenciar trazendo à tona a falta 
de padrão no comportamento das empresas de mesma atividade econômica e localização distinta, podendo ser consequência da forma como o órgão ambiental fiscaliza os empreendimentos. Em comum para as duas regionais tem-se o não cumprimento de condicionantes (VTE 3) e a maioria de empreendimentos com autos de infração (VTE 6), indicando não conformidade com a legislação ambiental, confirmando o descrito por vários autores que a etapa de pós-licenciamento não é desenvolvida satisfatoriamente pelos empreendedores (DIAS, SÁNCHEZ, 2001; PRADO FILHO, SOUZA, 2004; FABRI, CARNEIRO, LEITE, 2008; ALMEIDA; MONTAÑO, 2015; SANTIAGO, ALVARENGA, ALMEIDA, 2016).

Focando nas VTPs (Figura 7), para verificar a solicitação de documentos complementares pelas Suprams, foi analisado o desempenho da VTP 3, na qual Santiago (2015) demonstrou que cerca de $70 \%$ dos processos apresentaram solicitação de documentos complementares para esclarecer falhas dos estudos ambientais e/ou alguma irregularidade encontrada no processo ou durante vistoria do empreendimento, não sendo diferente na Supram TMAP, na qual cerca de $90 \%$ dos processos apresentaram solicitação de complementos.

Figura 7 - Comparação entre os Índices de Concordância de Variáveis (TV) para as VTPs da Supram Sul de Minas (a) (Santiago, 2015) e da Supram TMAP (b) (resultado deste trabalho)
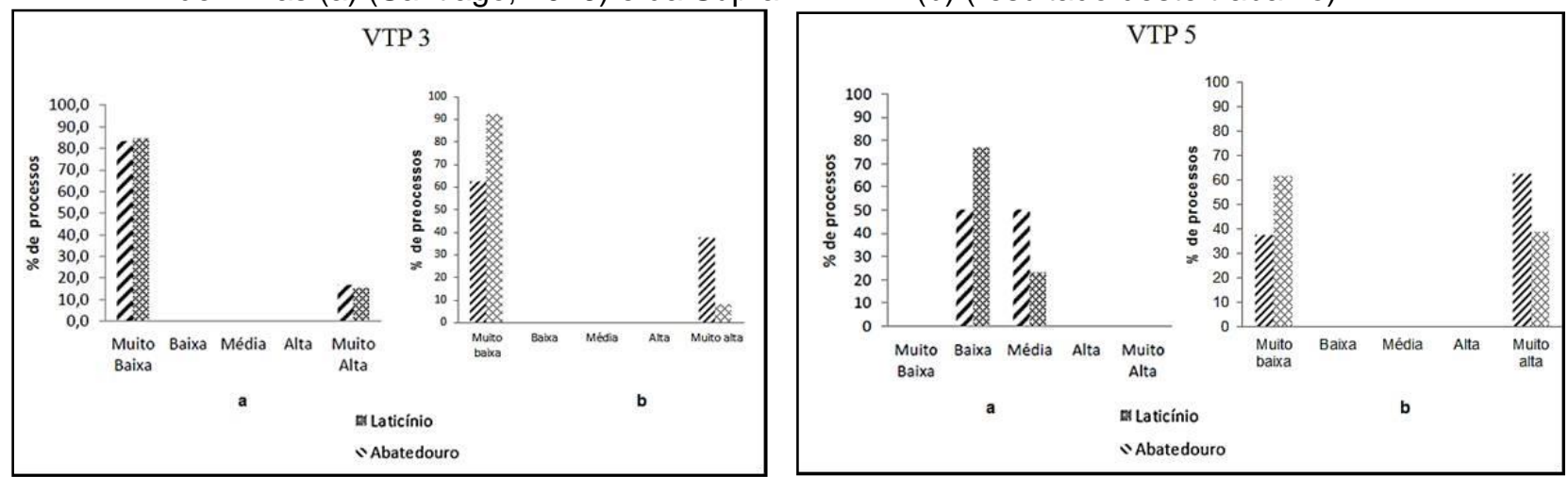

Fonte: Elaborado pelas autoras.

O cenário apresentado pela VTP 3 vai ao encontro com a afirmação de Almeida (2010) para a Supram Sul de Minas, de que os estudos aprovados pelo órgão ambiental são insatisfatórios e incapazes de fornecer informações que atestem a viabilidade ambiental dos empreendimentos, e se repete na Supram TMAP.

A VTP 5, que indica a presença de acompanhamento por parte do órgão ambiental, apresentou um comportamento diferente entre a Supram Sul de Minas e TMAP (Figura 7). $\mathrm{Na}$ regional Sul de Minas, os indícios de acompanhamento nos processos foram 
classificados como "Baixa" a "Média" enquanto na TMAP cerca da metade dos processos constavam indicativos de acompanhamento, classificando-se como "Muito alta". Entretanto, a outra metade dos processos da regional TMAP encontra-se como "Muito Baixa", caracterizando a checagem de cumprimento de monitoramento somente na renovação da licença, ou seja, casos em que não há acompanhamento, fato este também destacado por Santiago (2015).

Analisando as duas VTPs que possibilitaram comparação entre os dois trabalhos, novamente destaca-se a similaridade entre as Suprams na variável burocrática (VTP 3) e o distanciamento de comportamento na etapa pós-licenciamento propriamente dita (VTP 5). É importante ressaltar que as regionais possuem diferenças de jurisdição, a Supram Sul de Minas atende 176 municípios, enquanto que a Supram TMAP abrange 67 municípios (MINAS GERAIS, 2017), fato que dificulta o acesso e deslocamento para o acompanhamento dos empreendimentos.

A Figura 8 demonstra, para cada empreendimento analisado, quantos relatórios foram solicitados pelo órgão ambiental na concessão da licença e quantos foram encontrados nos processos dos empreendimentos. Santiago (2015) destacou que na Supram Sul de Minas foi encontrado uma expressiva heterogeneidade entre o número e periodicidade de entrega dos relatórios de automonitoramento, fato também visto na Supram TMAP.

É notório que o número de relatórios entregues pelos empreendedores na Supram TMAP é menor que na regional Sul de Minas (Figura 8), o que pode ser um reflexo da falta de acessibilidade e organização dos processos encontrados nesta Supram, não podendo afirmar ao certo, que não foram protocolados.

No Quadro 3, é possível observar melhor o cenário do automonitoramento da Supram TMAP. Nota-se que para apenas quatro dos empreendimentos analisados desta regional foram encontrados mais de $50 \%$ de relatórios exigidos (A2, A3, L5 e L6). 
Figura 8 - Entrega dos relatórios de automonitoramento pelos empreendimentos. Supram Sul de Minas (a) (Santiago, 2015) e da Supram TMAP (b) (resultado deste trabalho)

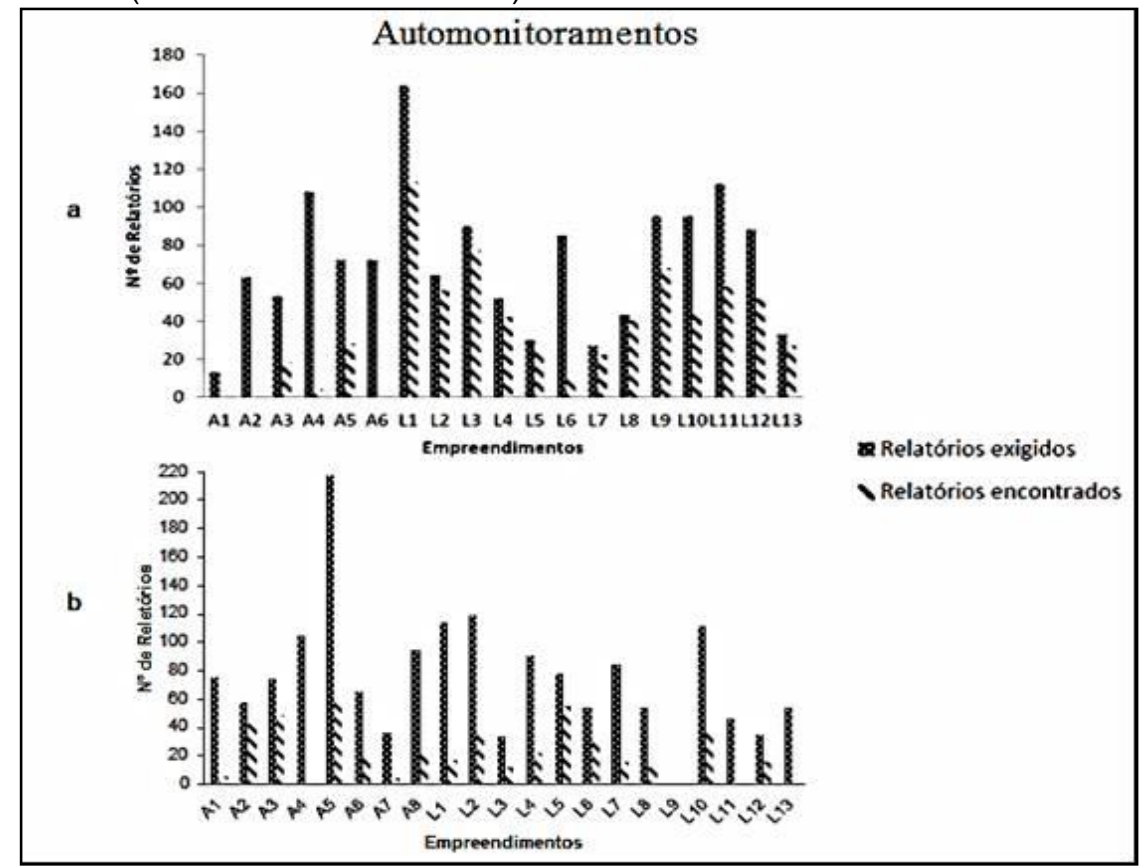

Fonte: Elaborado pelas autoras.

Quadro 3 - Porcentagem de relatórios de automonitoramento encontrados para cada empreendimento analisado na Supram TMAP

\begin{tabular}{|c|c|c|c|c|c|}
\hline $\begin{array}{c}\text { Empreendiment } \\
\mathbf{0}\end{array}$ & $\begin{array}{c}\text { Relatórios } \\
\text { encontrado } \\
\mathbf{s}(\%)\end{array}$ & Empreendimento & $\begin{array}{c}\text { Relatórios } \\
\text { encontrado } \\
\mathbf{s}(\%)\end{array}$ & $\begin{array}{c}\text { Empreendiment } \\
\mathbf{0}\end{array}$ & $\begin{array}{c}\text { Relatórios } \\
\text { encontrado } \\
\mathbf{s}(\%)\end{array}$ \\
\hline A1 & 5,4 & $\mathrm{~A} 8$ & 23,6 & $\mathrm{~L} 7$ & 18,1 \\
\hline $\mathrm{A} 2$ & 73,2 & $\mathrm{~L} 1$ & 14,0 & $\mathrm{~L} 8$ & 20,7 \\
\hline $\mathrm{A} 3$ & 65,7 & $\mathrm{~L} 2$ & 28,0 & $\mathrm{~L} 9$ & 0 \\
\hline $\mathrm{A} 4$ & 0 & $\mathrm{~L} 3$ & 34,4 & $\mathrm{~L} 10$ & 31,5 \\
\hline $\mathrm{A} 5$ & 27,2 & $\mathrm{~L} 4$ & 23,6 & $\mathrm{~L} 11$ & 0 \\
\hline A6 & 26,6 & $\mathrm{~L} 5$ & 71,0 & $\mathrm{~L} 12$ & 41,2 \\
\hline A7 & 8,6 & $\mathrm{~L} 6$ & 52,9 & $\mathrm{~L} 13$ & 0 \\
\hline
\end{tabular}

Fonte: Elaborado pelas autoras.

Entretanto, nas duas Suprams, os problemas de falta de uniformidade no tratamento de processos de mesma atividade e deficiência no acompanhamento por parte do órgão ambiental se destacam, pois, por se tratar de uma etapa essencial para que a AIA cumpra seu papel de propiciar um efetivo gerenciamento ambiental (SADLER, 1996), os resultados obtidos deveriam ser mais próximos ao ideal.

\section{CONCLUSÕES}

Apesar da dificuldade de acesso às informações na Supram TMAP, foi possível verificar que os empreendimentos realizaram e entregaram o RCA e, na maioria, 
propuseram ações de mitigação e compensação para seus impactos identificados no PCA; porém, fica evidenciado nos relatórios e pareceres técnicos que a execução destes projetos não ocorreu satisfatoriamente, sendo refletido com cumprimento insatisfatório de condicionantes, incluindo o automonitoramento.

Esse fato pode estar relacionado à falta de acompanhamento e fiscalização de empreendimentos licenciados por parte do órgão ambiental, visto que as variáveis que analisavam esses itens resultaram em condições insatisfatórias na atuação dos servidores.

Portanto, com o estudo de caso foi possível observar que a maioria dos empreendimentos apresentou um baixo desempenho ambiental na fase pós-licenciamento, tanto por parte dos empreendedores como do órgão ambiental, o qual também não alcançou um desempenho satisfatório no acompanhamento e fiscalização desta etapa, além de sugerir a falta de padronização nos procedimentos adotados para empreendimentos de mesma tipologia, porém, em localizações distintas e sob jurisdição de diferentes Suprams.

Por fim, sugere-se que novas pesquisas sejam realizadas, a fim de avaliar o desempenho do órgão ambiental, mais precisamente do novo núcleo criado (NUCAM), atual responsável pela etapa de pós licenciamento em MG. Além disso, novos estudos devem destacar os possíveis pontos de melhoria no órgão, como o déficit de pessoal, disponibilidade de recursos e acesso à informação.

\section{REFERÊNCIAS}

ALMEIDA, M. R. R. Análise da qualidade de relatórios de controle ambiental aprovados pela Superintendência Regional de Meio Ambiente e Desenvolvimento Sustentável do Sul de Minas Gerais. 2010. 154f. Dissertação (Mestrado em Meio Ambiente e Recursos Hídricos) Instituto de Recursos Naturais, Universidade Federal de Itajubá, Itajubá, 2010.

ALMEIDA, M. R. R. Aplicação da abordagem sistêmica para análise da efetividade da Avaliação de Impacto Ambiental no Brasil: um estudo para os estados São Paulo e Sul de Minas Gerais. 2013. 172f. Tese (Doutorado em Ciências da Engenharia Ambiental) - Escola de Engenharia de São Carlos, Universidade de São Paulo, São Carlos, 2013.

ALMEIDA, M. R. R.; ALVARENGA, M. I. N; CESPEDES, J. G. Avaliação da qualidade de estudos ambientais em processos de licenciamento. Geociências, v. 33, n. 1, p. 106-118, 2014.

ALMEIDA, M. R. R.; MONTAÑO, M. Benchmarking na avaliação de impacto ambiental: o sistema mineiro frente às melhores práticas internacionais. Sociedade \& Natureza, v. 27, n. 1, p.81-96, 2015. https://doi.org/10.1590/1982-451320150106

BRASIL. Constituição (1988). Constituição da República Federativa do Brasil. Brasília, DF: Senado Federal, 1988. Disponível em:

http://www.planalto.gov.br/ccivil 03/constituicao/constituicao.htm. Acesso em: 21 maio 2017. 
BRASIL. Tribunal de Contas da União. Trabalhos de fiscalização de obras públicas integrantes do orçamento da união referentes ao exercício de 2009 - TC-027.609/2008-3. Brasília: Tribunal de Contas da União (TCU). 2008.

$\mathrm{CNI}$ - Confederação Nacional da Indústria (Brasil). Proposta da indústria para o aprimoramento do licenciamento ambiental. Brasília: CNI. 2013. 88p.

COPAM - Conselho Estadual de Política Ambiental (Minas Gerais). Deliberação Normativa $\mathbf{n}^{\circ} \mathbf{7 4}$ de 09 de Setembro de 2004. Estabelece critérios para classificação, segundo o porte e potencial poluidor, de empreendimentos e atividades modificadoras do meio ambiente passíveis de autorização ou de licenciamento ambiental no nível estadual, determina normas para indenização dos custos de análise de pedidos de autorização e de licenciamento ambiental, e dá outras providências Belo Horizonte, 2004. Disponível em:

http://www.siam.mg.gov.br/sla/download.pdf?idNorma=37095. Acesso em: 7 ago. 2017.

CONAMA - Conselho Nacional do Meio Ambiente (Brasil). Resolução n 237 de 19 de Dezembro de 1997. Brasília, 1997. Disponível em:

http://www.siam.mg.gov.br/sla/download.pdf?idNorma=2080. Acesso em: 7 ago. 2017.

DIAS, E. G.C.S.; SÁNCHEZ, L. E. Deficiências na implementação de projetos submetidos à avaliação de impacto ambiental no Estado de São Paulo. Revista de Direito Ambiental, v.6, n.23, p.163-204, 2001.

FABRI, E. S.; CARNEIRO, M. A.; LEITE, M. G. P. Diagnóstico dos processos de licenciamento e fiscalização das pedreiras de rochas ornamentais na região Centro-sul de Minas Gerais. REM: International Engineering Journal, v. 61, n. 3, p. 279-284, 2008. https://doi.org/10.1590/S0370$\underline{44672008000300003}$

FERNANDES, A. T.; CASTRO, C.; MARON, J. Desafios para implementação de políticas públicas: intersetorialidade e regionalização. In: CONGRESSO CONSAD DE GESTÃO PÚBLICA, 4., 2013. Brasília. [Anais...] Brasília, DF: Conselho Nacional de Secretários de Estado da Administração, 2013. p. 20.

FLORENCIO, E. O Automonitoramento no Estado de Minas Gerais: estudo de caso: bacia hidrográfica do rio Itabirito. 2010. 134f. Dissertação (Mestrado em Sustentabilidade Socioeconômica e Ambiental) - Universidade Federal de Ouro Preto, 2010.

FONSECA, A.; RESENDE, L. Boas práticas de transparência, informatização e comunicação social no licenciamento ambiental brasileiro: uma análise comparada dos websites dos órgãos licenciadores estaduais. Engenharia Sanitária Ambiental, v.21, n.2, p. 295-306, 2016. https://doi.org/10.1590/s1413-41522016146591

GRINOVER, A. P. Defesa do meio ambiente em juízo como conquista da cidadania. 2014. Disponível em: http://www.jf.jus.br/ojs2/index.php/revcej/article/view/244/406. Acesso em: 6 jan. 2017.

MINAS GERAIS. Decreto no 21.228, de 10 de Março de 1981. Regulamenta a Lei no 7.772, de 08 de setembro de 1980, que dispõe sobre a proteção, conservação e melhoria do meio ambiente no Estado de Minas Gerais. Belo Horizonte, 1981. Disponível em:

http://www.siam.mg.gov.br/sla/download.pdf?idNorma=1098. Acesso em: 15 jun. 2017.

MINAS GERAIS. Decreto no 47.042 de 06 de Setembro de 2016. Dispõe sobre a organização da Secretaria de Estado de Meio Ambiente e Desenvolvimento Sustentável. Belo Horizonte, 2016.Disponível em: https://www.almg.gov.br/consulte/legislacao/completa/completa-nova- 
min.html?tipo=DEC\&num $=47042 \&$ comp $=\& a n o=2016 \&$ texto=consolidado\#texto. Acesso em: 15 jun. 2017.

MINAS GERAIS. Secretária Estadual de Meio Ambiente e Desenvolvimento Sustentável. Licenciamento. Disponível em: http://www.Semad.mg.gov.br/Suprams-regionais/limites. Acesso em: 05 jun. 2017

MINAS GERAIS. Decreto no 47.383 de 2 de Março de 2018. Estabelece normas para licenciamento ambiental, tipifica e classifica infrações às normas de proteção ao meio ambiente e aos recursos hídricos e estabelece procedimentos administrativos de fiscalização e aplicação das penalidades. Belo Horizonte, 2018. Disponível em:

https://www.almg.gov.br/consulte/legislacao/completa/completa-novamin.html?tipo=DEC\&num=47383\&comp=\&ano=2018\&texto=original\#texto. Acesso em: 17 mar. 2018.

PELLIN, A.; LEMOS, C. C.; TACHARD, A.; OLIVEIRA, I. S. D.; SOUZA, M. P. Avaliação Ambiental Estratégica no Brasil: considerações a respeito do papel das agências multilaterais de desenvolvimento. Engenharia Sanitária e Ambiental, v.16, n.1, p. 27-36, 2011. https://doi.org/10.1590/S1413-41522011000100006

PRADO FILHO, J. F.; SOUZA, M. P. O licenciamento ambiental da mineração no quadrilátero ferrífero de Minas Gerais - uma análise da implementação de medidas de controle ambiental formuladas em EIAs/RIMAs. Engenharia Sanitária Ambiental, v. 09, n. 04, p. 343-349, 2004. https://doi.org/10.1590/S1413-41522004000400012

SÁNCHEZ, L. E.; GALLARDO, A. L. C. F. On the successful limplementation of mitigation measures. Impact Assessment and Project Appraisal, v. 23, n. 3, p. 182-190, 2005. https://doi.org/10.3152/147154605781765472

SÁNCHEZ, L. E. Avaliação de impacto ambiental: conceitos e métodos. São Paulo: Oficina de Textos, 2008, 495p.

SANTIAGO, C. S. Avaliação da etapa de acompanhamento do licenciamento ambiental de abatedouros e laticínios em Minas Gerais. 2015. 77f. Dissertação (Mestrado em Meio Ambiente e Recursos Hídricos) - Universidade Federal de Itajubá, MG, 2015.

SANTIAGO, C. S.; ALVARENGA, M. I. N.; ALMEIDA, M. R. R. Avaliação da etapa de acompanhamento do licenciamento ambiental de abatedouros e laticínios em Minas Gerais.

Revista Brasileira de Geografia Física, v. 9, n. 3, p.940-954, 2016. DOI:

https://doi.org/10.26848/rbgf.v9.3.p940-954

SCHERER, M. Análise da qualidade técnica de estudos de impacto ambiental em ambientes de Mata Atlântica de Santa Catarina: abordagem faunística. Biotemas, v.24, n.4, p.171-181, 2011. https://doi.org/10.5007/2175-7925.2011v24n4p171

SADLER, B. (Org.)Environmental assessment in a changeling world, evaluating practice to improve performance. Ottawa: Canadian Environmental Assessment, 1996. 248p.

SILVA, C. M. Licenciamento Ambiental e Gestão Pública no Estado de Minas Gerais. 2009. 169f. Dissertação (Mestrado em Administração Pública) - Fundação João Pinheiro, Belo Horizonte, 2009.

SILVEIRA, R. L. Avaliação dos métodos de levantamento do meio biológico terrestre em estudos de impacto ambiental para a construção de usinas hidrelétricas na região do 
Cerrado. 2006. 65f. Dissertação (Mestrado em Ecologia Aplicada) - Escola Superior de Agricultura Luiz de Queiroz, Piracicaba, 2006.

VIANA, M. B. Licenciamento ambiental de minerações em Minas Gerais: novas abordagens de gestão. 2007. 305f. Dissertação (Mestrado em Desenvolvimento Sustentável) - Centro de Desenvolvimento Sustentável, Universidade de Brasília, Brasília. 2007.

VIOLA, E. J. O movimento ecológico no Brasil (1974 - 1986): do ambientalismo à ecopolítica.

Revista Brasileira de Ciências Sociais, v. 1, n. 3, p. 5-26, 1987. 